\title{
ASD intervention research in real world contexts: Refining single case designs
}

Kim Bulkeley

Anita Bundy

Jacqueline Roberts

Stewart Einfeld (TBC)

Keywords: autism; social validity; repeated measures; individualised intervention; outcome measurement; intervention fidelity

\begin{abstract}
:
There is a pressing need for intervention research that reflects real world practice to support evidence based decision making for families, professionals and administrators who support children with ASD. Some of the challenges confronting intervention research are explored, with solutions offered based on single case design methodology. Challenges with single case designs are also outlined and contemporary solutions that are applicable in real world contexts are illustrated in a study in progress by the authors. Research designs utilizing these strategies may assist with mobilizing the contribution of practitioners in bridging the research to practice gap in intervention with young children with ASD.
\end{abstract}

\section{Introduction:}

Intervention research that reflects real world contexts is required by service users, professionals, and policy makers to understand how to promote the best outcomes for individuals with autism 
spectrum disorders (ASD) and to decide which interventions will be funded by public administrations. The presentation of children with ASD has grown significantly (Johnny.L. Matson \& Kozlowski, 2011), with a prevalence of 1 in 88 recently reported (Centers for Disease Control and Prevention, 2012). The cost to governments and communities who support those with ASD is significant, with individual estimates as high as $\$ 3.2$ million throughout the lifespan (Ganz, 2007). Effective interventions, particularly if they are provided early, can improve outcomes, reducing the cost of support by up to $65 \%$ across the life-course (National Autism Centre, 2009).

There are a plethora of reviews of intervention evidence (Klintwall, Gillberg, Bolte, \& Fernell, 2012; LeBlanc \& Gillis, 2012; National Autism Centre, 2009; Prior, Roberts, Rodger, Williams, \& Sutherland, 2011; Roberts \& Prior, 2006) describing interventions that meet some of the needs of some of these children (Stahmer, Schreibman, \& Cunningham, 2011). However, we lack information to support many of the interventions in current use and recent findings suggest that families and professionals regularly use a wide range of interventions with little or no empirical support (Carter et al., 2011; Goin-Kochel, Myers, \& Mackintosh, 2007; Hess, Morrier, Heflin, \& Ivey, 2008; Stahmer, 2007). Clearly, more research into contemporary interventions is required.

Intervention research for all children with disabilities is notoriously difficult, lags behind the experience of families and professionals, and is not readily translated into real world usage (Odom, Hume, Boyd, \& Stabel, 2012). In a review of scientific methods in special education, including children with autism, Odom (2005) claimed that research in this field is "hardest-to-do science" reflecting the complexity of the participant group. 
The costs associated with conducting research are one serious impediment to the comprehensive investigation of interventions, particularly for children with ASD (Mesibov \& Shea, 2011). Time and money are spread thinly across a diverse range of areas, highlighting the need for designs that use minimal additional resources, produce robust results and yield practice-ready outcomes. Facilitating collaborative research with service providers in real world settings has the potential to spread limited research resources further and improve the usability and quantity of intervention research (Jenkins, Price, \& Straker, 1998).

Ecological and social validity are primary factors to be considered alongside scientific rigor when designing intervention research for young children with autism (Dingfelder \& Mandell, 2011). Testing of interventions in controlled experimental environments prior to application in real world settings (i.e., the efficacy-to-effectiveness pipeline) is viewed widely as rigorous research process (Smith et al., 2007). However, in the attempt to follow rigorous practices, researchers may divorce interventions from a real world context, conducting studies that do not apply to families and practitioners. The exploration of research designs that are scientifically sound as well as ecologically and socially valid is a challenge facing contemporary intervention research (Dingfelder \& Mandell, 2011). An alternative research frame is needed that would result in optimal outcomes for individuals, use eclectic approaches that are individually tailored, and include socially valid outcome measurement (Mesibov \& Shea, 2011).

Single case design (SCD) research is often touted as a way to solve some of the problems with ASD intervention research and, indeed, it can do that. In Table 1, we compare common research designs in terms of problems solved. However SCDs are also associated with particular research 
challenges. In this paper, we provide an overview of issues readily addressed by SCDs in developing low cost research designs that can be conducted in real world practice settings. We then explore problem areas associated with SCD research. Finally, we describe ways that we solved some of the problems of SCDs, illustrating these with a study in progress.

\section{Insert table about here}

\section{What problems are overcome using single case design research?}

While no one research design can claim exclusive superiority for evaluating the effectiveness of interventions with children with autism, SCDs show promise for building a socially and ecologically valid evidence base. SCDs can be undertaken in real world settings, reflect sound science and have the capacity to identify functional links between intervention and behavioural responses (Kazdin, 2011). SCDs are low-cost, flexible and can be applied by practitioners with minimal modification to real world practice. SCDs can mobilise the contribution of practitioners to the development of a contemporary evidence base (R. Horner et al., 2005; Perdices \& Tate, 2009), helping to close the research-to-practice gap. A comprehensive overview of SCD approaches can be found in texts by Kazdin (2011) and Gast (2010) devoted to this topic specifically.

\subsection{Experimental Design}

SCDs have been proposed as a robust mechanism for intervention research in occupational therapy (Johnston \& Smith, 2010), special education (R. Horner, et al., 2005; Kratochwill et al., 2010) and autism (J. L. Matson, Turygin, Beighley, \& Matson, 2012; Odom et al., 2003).

Originating in the applied behaviour analysis field, SCDs are now widely used; have been included in recent ASD intervention research reviews (National Autism Centre, 2009); and are 
gaining support as a source of high level evidence in intervention research (Kratochwill, et al., 2010; Perdices \& Tate, 2009). Awareness of the value of this methodology has led to the development of tools for scrutinising ?research quality (Kratochwill, et al., 2010; Logan, Hickman, Harris, \& Heriza, 2008; Tate et al., 2008) and ongoing efforts to develop systems for aggregating the findings of this growing body of research through meta-analysis (Parker, Vannest, \& Davis, 2011; Wolery, Busick, Reichow, \& Barton, 2010).

\subsubsection{Control group}

Concerns have been raised about the ethics and resource implications of including control groups in intervention research with young children with ASD (Lord et al., 2005). SCDs remove the need for a control group as individual participants act as their own controls via multiple phases where the independent variable is manipulated. The ethical issues of withholding treatment are minimized or removed as all participants receive treatment in the course of the study with relatively brief delays in access. Furthermore, if there is risk of harm to the participant by delaying treatment, as in the case of self injurious behaviour, there are SCD options that remove an initial pre-intervention baseline period, providing comparison treatment phases of a brief duration. The SCD method provides a range of options to manage ethical issues presented by the need to establish experimental control (Kazdin, 2011). The increased cost of providing intervention to a large number of participants, both intervention and control, over the life of a group design study are not encountered in a SCD as the participant numbers are significantly smaller. 


\subsubsection{Real world practice and social validity}

SCD research is a robust scientific method that can be applied in practice and community settings. The nature of SCD, with a focus on individual participants, allows for the establishment of outcome measures and targets of intervention that are aligned with the preferences and priorities of participants, families and other service providers, thus enhancing the social validity of the research (Perdices \& Tate, 2009).

\subsection{Small Numbers of Participants}

SCDs can yield robust findings with a small number of participants, solving problems with recruitment that abound in ASD research with children. Families with children with ASD have significant levels of stress (Lovell, Moss, \& Wetherell, 2012) and are reported to engage in multiple and intensive interventions (Green et al., 2006). Research activity, no matter how important, adds to their stress, reducing the likelihood of participation in research. In addition, due to the heterogeneous nature of ASD, recruitment of large numbers of participants that are sufficiently similar can be problematic. SCDs require a small number of participants, making it easier to focus on a clearly defined participant group and to apply narrow inclusion criteria with some confidence of recruiting adequate numbers of participants to make the design work.

\subsubsection{Generalisation of findings}

The external validity of SCD studies is a hotly debated concept, with some experts suggesting that this method provides the most relevant research for the population of interest (Keenan \& Dillenburger, 2011) and others criticizing SCD research for the use of small numbers that limit 
generalisability (Smith, et al., 2007). External validity is strengthened by including multiple participants (at least 3 replications across participants), clearly describing participants, operationalising the context where intervention is provided, and replicating the study across sites with independent research groups (R. Horner, et al., 2005). The development of single case research designs that encourage replication across real world settings can assist with improving the external validity of the intervention evidence base for ASD interventions using SCDs.

\subsection{Individualising of Interventions}

SCDs support the administration of individualised interventions to participants. SCDs establish participants as their own controls, allowing for the development of individualised protocols (independent variable) within a consistent framework that allow for comparison across participants (Mesibov \& Shea, 2011). Individualised variation in intervention for young children with ASD is regarded as best practice (Barton, Lawrence, \& Deurloo, 2012; Delmolino \& Harris, 2012; Strain, Schwartz, \& Barton, 2011); a one-size-fits-all approach is rarely appropriate. In a $\mathrm{SCD}$, a hypothesis is formed from careful observation about the best strategies to apply within the overall intervention framework. Intervention is undertaken with ongoing monitoring to track individual responses and outcomes. Articulating consistent intervention principles as part of the SCD protocol provides sufficient clarity to allow replication of the intervention in future research and to distinguish one intervention approach from another for an individual child (Mesibov \& Shea, 2011).

\subsubsection{Intervention Fidelity}

Measurement of intervention fidelity, commonly overlooked in research, confirms that participants receive an intervention as proposed (Wolery, 2011). In addition, measurement of 
fidelity ensures transparency in the differentiation of intervention types when two or more interventions are applied (Kazdin, 2011), thus adding strength to claims of influence on outcomes (S. Horner, Rew, \& Torres, 2006). The individualising of interventions raises challenges for the measurement of fidelity and heightens the need for clear processes for confirming the nature of the interventions provided in research protocols. Audio recordings show promise for intervention fidelity measurement (Bellg et al., 2004; Torrey, 2012). Audio recordings of intervention sessions are unobtrusively obtained using digital recording devices and provide a good source of material for analysis by independent raters. Checklists of expected features of the interventions can be established for rating of quality and content of interventions by an independent rater and for differentiation of interventions over the course of the service delivery.

\subsection{Understanding individual treatment response}

The nature of ASD as a spectrum disorder implies the variety of individuals who are included in this category and forewarns of the need to understand individual responses to intervention. The individual treatment (dependent variable) response story is not told by group designs where participant data are aggregated to determine effectiveness, masking much of the variability that is often demonstrated by participants (R. Horner, et al., 2005; Smith, et al., 2007). SCDs focus on the individual as the unit of concern, and report specific and detailed information on the response of individual participants on repeated occasions throughout the phases of the research. This information may establish a functional link between treatment and response, generate hypotheses about differential treatment responses, inform intervention decisions, provide empirical support for current practice and highlight targets for future research (Kazdin, 2011). 


\section{How can the problems encountered in single case designs be solved?}

SCDs are not without their limitations, but there are a variety of design options to manage the challenges presented by ASD intervention research (see Table 1). The capacity to withdraw an intervention; appropriate repeated measurement; rater bias; multiple rater complications; assessment of maintenance; and the contextualising of non-standardised ratings present challenges in conducting SCDs with young children with ASD.

\subsection{Repeated measurement tools}

Measurement tools that are acceptable in context, focus on specific, individualised performance (Johnny. L. Matson, 2007) and can be applied repeatedly are required for ASD intervention research (Kasari, 2002). The relevance and ecological validity of outcome measurement has not been widely addressed in the SCD literature specifically, but is of great importance to the practical significance of the outcomes achieved in intervention research (Gast, 2010). The exploration of measurement options that are suitable for SCDs in natural settings is a challenge to the application of these designs in ASD intervention research.

A key feature of SCD research is the need for short-interval, repeated measurement of the dependent variable. The repeated measure requires a platform that is user-friendly, efficient, consistent, and that reduces the imposition of frequent ratings, especially in natural contexts. Many mechanisms have been used for collecting repeated measurement data: behavioural observations manually recorded during treatment sessions (Dykstra, Boyd, Watson, Crais, \& Baranek, 2012), computer-based recording of observations (Gast, 2010), video recordings (Boyd, McDonough, Rupp, Khan, \& Bodfish, 2011), and partial interval recording (Davis, Durand, \& Chan, 2011). These all require significant resources, both at the point where intervention is provided and in analysis of the data. In real world contexts, where practitioner/researchers often 
work in home or community settings, it is not possible to use measurement tools that require an inordinate level of resourcing.

The engagement of parents or carers in the repeated measurement of behaviour and the development of instruments that are sensitive and specific to the perceived needs of children from a service user perspective are emerging as an important part of understanding the social validity of the outcomes of intervention (Adams et al., 2012). SCDs in ASD may benefit from measurement approaches that embrace this perspective, generating evidence that is defensible and readily applied in real world settings.

Visual analogue scales have been used in SCDs (Hoogeboom et al., 2012) and show great promise in addressing some of these concerns. They are inexpensive, individualised, flexible, defensible, efficient and user friendly. VASs are also readily transferred onto a variety of electronic and hard copy media for simple and accurate completion (Dale \& Hagen, 2007; Wewers \& Lowe, 1990).

\subsubsection{Rater Drift}

Rater drift is another important issue that requires careful consideration in the design of repeated measurement (Wewers \& Lowe, 1990). The tendency to change the focus from the original target of concern as priorities change can be managed by incorporating a description of the target behaviour within the repeated measurement rating tool. A clear reminder of the target behaviour is an essential starting point to ensure consistency in the recognition of the behaviour of concern (Gast, 2010).

\subsubsection{Rater bias}

Rater bias, also known in this case as a placebo effect, has been recognised as an important consideration in intervention research using parent-report outcome measures (Lord, et al., 2005). 
For any number of reasons, parents of young children with ASD are likely to report positive outcomes for the majority of interventions (Goin-Kochel, Mackintosh, \& Myers, 2009). Many SCDs offer a single intervention interspersed with baseline phases. SCDs do not readily manage blinding of raters, essential to the objectivity of repeated ratings. These problems are heightened when parents and carers rate a child's performance in natural contexts. Including two interventions that are both potentially effective provides a degree of rater blinding, and allows for comparison of differential intervention effects.

\subsubsection{Multiple raters}

Multiple raters can threaten the quality of measurement, which is heightened in SCDs due to the increased frequency of behaviour rating. These factors are difficult to control and may be managed by a series of reliability comparisons between raters until acceptable levels of agreement are obtained (Gast, 2010; Ottenbacher, 1986). In real world settings, repeated training imposes a significant burden on raters. One option, commonly employed in SCD, is to remove the rating of performance from the setting by training raters who are independent to the provision of the intervention to rate from videotape (Kazdin, 2011). However, this may not be a viable solution when project resources cannot sustain the imposition of repeated video recording and the lengthy process of rating video excerpts.

The engagement of parents and carers as raters provides an important source of information about the lived experience of the performance of the child (Adams, et al., 2012) and the social and ecological validity of the changes in behaviour as a result of interventions (Chafouleas, Sanetti, Kilgus, \& Maggin, 2012). The obvious limitations of data gained in this way can be 
managed by engaging a single rater (Chafouleas et al., 2010) for the duration of the study and including other mechanisms for validation and contextualising of the behaviours.

\subsubsection{Contextualising of measures}

The individualised and repeated measurement of outcomes is a feature of SCDs that is highly valued for its social and ecological validity (Perdices \& Tate, 2009). Standardised instruments may not be applicable in SCDs due to limitations in their re-application over short intervals and a lack of specificity of items. However, an understanding of where behaviour ratings fall in relation to a larger group of similar individuals assists with contextualizing the extent of the difficulties experienced and may provide insight into the broader clinical significance of changes in behaviour over time (Johnston \& Smith, 2010). The use of standardised behaviour rating scales is an option that can be incorporated into a SCD at baseline and follow up to assess participants behaviour in a contextualized manner and supplement individualised repeated measures data.

\subsection{Inability to Withdraw Intervention}

Demonstration of a functional link between behaviour change and the introduction of an intervention is the essence of intervention research. In SCDs, a baseline phase followed by a single intervention phase (i.e., A-B) provides a relatively weak demonstration of functional linkage as there is no measurement of the impact of removal of the independent variable (Johnston \& Smith, 2010). When a return-to-baseline phase is included (i.e., A-B-A) showing behaviour returning to pretreatment levels (Kazdin, 2011), the functional link between behaviour change and intervention is strengthened. However, when interventions make permanent changes 
(e.g., building skills), often the case with interventions delivered to children with ASD (Lord, et al., 2005), the removal of intervention will not demonstrate a functional link and there is a need to find other ways of demonstrating the link between intervention and behaviour change. One option is to use a multiple baseline design where there are multiple participants or where an intervention is introduced across several behaviours with one participant (Kazdin, 2011). The intervention is introduced at different points with varying lengths of baseline to support the link between behaviour change and intervention. Running multiple baselines across behaviours with

the one individual is problematic, however, when the intervention involves building the skills of parents or carers who may in turn apply, albeit inadvertently, the intervention to all situations, thereby invalidating the benefits of the design. Another option is to establish a protocol that uses two interventions from different theoretical frameworks and apply them in a random order (ABAC of $\mathrm{ACAB})$. This design demonstrates a treatment effect across participants; does not need to occur concurrently; and accommodates the inability to withdraw the treatment.

\subsection{Maintenance of change}

SCD research generally has a focus on short term interventions and immediate measures of outcome which provide little information on the maintenance of observed changes in behaviour over time (Smith, et al., 2007). Measurements of outcomes are very intensively applied and are difficult to sustain. The inclusion of a probe phase, reapplying the repeated measure tool after a break of some weeks or months, provides an option for long-term follow up of the target behaviour (Finnigan \& Starr, 2010; Gutman et al., 2010). A probe phase maintains the integrity of the repeated measurement tool, which may be compromised by learning effects and rater 
fatigue, by providing a break from repeated measurement and extending the period over which outcomes are measured.

\section{Discussion}

We have identified research design problems that impede the conduct of intervention research for young children with autism spectrum disorders in natural settings, the strengths and weaknesses of SCD research and the potential refinement of SCDs for intervention research with children with ASD. SCD research is identified as a robust experimental method, providing potential solutions to problems with recruitment, limited funding for research, ethical issues of withholding intervention, individualising of interventions and understanding of individual intervention responses. SCDs also support the conduct of research in practice environments and the mobilization of practitioners in the generation of empirical support for interventions (Perdices \& Tate, 2009). Problems with SCDs were identified and solutions developed by incorporating novel design features borrowed from a range of research approaches. Solutions also were found to strengthen the functional link between intervention and behaviour change, measurement of intervention fidelity, suitability of repeated measurement tools, reduction of rater bias, rigor of rating procedures, measurement of maintenance of change, generalisability of results and contextualising of outcome measures. A contemporary SCD is provided in Table 2, a study in progress by the authors, illustrating solutions to some of the SCD research challenges outlined in this paper.

Insert Table 2 about here 


\section{Conclusion}

The refinement of SCD research has the potential to yield a significant body of evidence that is easily interpreted by service users, service providers and service administrators. These research designs will enhance outcomes for young children with ASD by building practice based evidence to support evidence based practice.

Adams, C., Lockton, E., Freed, J., Gaile, J., Earl, G., McBean, K., . . Law, J. (2012). The Social Communication Intervention Project: A randomized controlled trial of the effectiveness of speech and language therapy for school-age children who have pragmatic and social communication problems with or without autism spectrum disorder. International Journal of Language and Communication Disorders, 47(3), 233-244.

Barton, E., Lawrence, K., \& Deurloo, F. (2012). Individualizing interventions for young children with autism in preschool. Journal of Autism \& Developmental Disorders, 42(6), 1205 1217. doi: 10.1007/s10803-011-1195-z

Bellg, A. J., Borrelli, B., Resnick, B., Hecht, J., Minicucci, D. S., Ory, M., . . Czajkowski, S. (2004). Enhancing treatment fidelity in health behavior change studies: best practices and recommendations from the NIH Behavior Change Consortium. Health Psychol, 23(5), 443-451. doi: 10.1037/0278-6133.23.5.443

2004-18051-001 [pii]

Boyd, B. A., McDonough, S. G., Rupp, B., Khan, F., \& Bodfish, J. W. (2011). Effects of a family-implemented treatment on the repetitive behaviors of children with autism. Journal of Autism and developmental disorders, 41(10), 1330-1341. 
Carter, M., Roberts, J., Williams, K., Evans, D., Parmenter, T., Silove, N., . . W Warren, A. (2011). Interventions used with an Australian sample of preschool children with autism spectrum disorders. Research in Autism Spectrum Disorders, 5, 1033-1041.

Centers for Disease Control and Prevention. (2012). Prevalence of Autism Spectrum Disorders Autism and Developmental Disabilities Monitoring Network, 14 sites, United States, 2008. Morbidity and Mortality Weekly Report, 61(3). Retrieved from http://www.cdc.gov/ncbddd/autism/index.html

Chafouleas, S. M., Briesch, A. M., Riley-Tillman, T. C., Christ, T. J., Black, A. C., \& Kilgus, S. P. (2010). An investigation of the generalizability and dependability of Direct Behavior Rating Single Item Scales (DBR-SIS) to measure academic engagement and disruptive behavior of middle school students. Journal of School Psychology, 48(3), 219-246.

Chafouleas, S. M., Sanetti, L. M. H., Kilgus, S. P., \& Maggin, D. M. (2012). Evaluating sensitivity to behavioral change using direct behavior rating single-item scales. Exceptional Children, 78(4), 491-505.

Dale, O., \& Hagen, K. B. (2007). Despite technical problems personal digital assistants outperform pen and paper when collecting patient diary data. Journal of Clinical Epidemiology, 60, 8-17. doi: 10.1016/j.jclinepi.2006.04.005

Davis, T. N., Durand, S., \& Chan, J. M. (2011). The effects of a brushing procedure on stereotypical behavior. Research in Autism Spectrum Disorders, 5(3), 1053-1058. doi: 10.1016/j.rasd.2010.11.011

Delmolino, L., \& Harris, S. (2012). Matching children on the autism spectrum to classrooms: a guide for parents and professionals. Journal of Autism \& Developmental Disorders, 42(6), 1197-1204. doi: 10.1007/s10803-011-1298-6 
Dingfelder, H., \& Mandell, D. (2011). Bridging the Research-to Practice Gap in Autism Intervention: An Application of Diffusion of Innovation Theory. Journal of Autism and Developmental Disorders, 41, 597-609. doi: 10.1007/s10803-0010-1081-0

Dykstra, J. R., Boyd, B. A., Watson, L. R., Crais, E. R., \& Baranek, G. T. (2012). The impact of the Advancing Social-communication And Play (ASAP) intervention on preschoolers with autism spectrum disorder. Autism, 16(1), 27-44. doi: 1362361311408933 [pii]

\section{$10.1177 / 1362361311408933$}

Finnigan, E., \& Starr, E. (2010). Increasing social responsiveness in a child with autism: a comparison of music and non-music interventions. Autism, 14(4), 321-348.

Ganz, M. L. (2007). The lifetime distribution of the incremental societal costs of autism. Archives of Pediatrics \& Adolescent Medicine, 161(4), 343-349.

Gast, D. L. (2010). Single Subject Research Methodology in Behavioral Sciences Retrieved from http://site.ebrary.com/lib/usydDoc?id=10341929\&ppg=356

Goin-Kochel, R., Mackintosh, V., \& Myers, B. (2009). Parental reports on the efficacy of treatments and therapies for their children with autism spectrum disorders. Research in Autism Spectrum Disorders, 3, 528-537. doi: 10.1016/j.rasd.2008.11.001

Goin-Kochel, R., Myers, B., \& Mackintosh, V. (2007). Parental reports on the use of treatments and therapies for children with autism spectrum disorders. Research in Autism Spectrum Disorders, 1(3), 195-209.

Green, V. A., Pituch, K. A., Itchon, J., Choi, A., O'Reilly, M., \& Sigafoos, J. (2006). Internet survey of treatments used by parents of children with autism. Research in Developmental Disabilities, 27(1), 70-84. 
Gutman, S. A., Raphael, E. I., Ceder, L. M., Khan, A., Timp, K. M., \& Salvant, S. (2010). The effect of a motor-based, social skills intervention for adolescents with high-functioning autism: Two single-subject design cases. Occupational Therapy International, 17(4), 188-197. doi: 10.1002/oti.300

Hess, K. L., Morrier, M. J., Heflin, L. J., \& Ivey, M. L. (2008). Autism treatment survey: services received by children with autism spectrum disorders in public school classrooms. Journal of Autism \& Developmental Disorders, 38(5), 961-971. doi: 10.1007/s10803007-0470-5

Hoogeboom, T. J., Kwakkenbos, L., Rietveld, L., den Broeder, A. A., de Bie, R. A., \& van den Ende, C. H. (2012). Feasibility and potential effectiveness of a non-pharmacological multidisciplinary care programme for persons with generalised osteoarthritis: a randomised, multiple-baseline single-case study. BMJ Open, 2(4). doi: 10.1136/bmjopen2012-001161

e001161 [pii]

bmjopen-2012-001161 [pii]

Horner, R., Carr, E., Halle, J., McGee, G., Odom, S., \& Wolery, M. (2005). The Use of SingleSubject Research to Identify Evidence-Based Practice in Special Education. Exceptional Children, 71(2), 165-179.

Horner, S., Rew, L., \& Torres, R. (2006). Enhancing Intervention Fidelity: A Means of Strengthening Study Impact. Journal for Specialists in Pediatric Nursing, 11(2), 80-89. Jenkins, S., Price, C. J., \& Straker, L. (1998). The Researching Therapist A Practical Guide to Planning, Performing and Communicating Research. New York: Churchill Livingstone. 
Johnston, M., \& Smith, R. (2010). Single Subject Designs: Current Methodologies and Future Directions. OTJR: Occupation, Participation and Health, 30(1), 4-10.

Kasari, C. (2002). Assessing Change in Early Intervention Programs for Children with Autism. Journal of Autism \& Developmental Disorders., 32(5), 447-461.

Kazdin, A. (2011). Single-Case Research Designs - Methods for clinical and applied setttings. New York: Oxford University Press.

Keenan, M., \& Dillenburger, K. (2011). When all you have is a hammer....: RCTs and hegemony in science. Research in Autism Spectrum Disorders, 5, 1-13. doi:

10.1016/j.rasd.2010.02.003

Klintwall, L., Gillberg, C., Bolte, S., \& Fernell, E. (2012). The efficacy of intensive behavioral intervention for children with autism: A matter of allegiance? [letter to the editor]. Journal of Autism and Developmental Disorders, 42, 139-140. doi: 10.1007/s10803-011$1223-\mathrm{z}$

Kratochwill, T. R., Hitchcock, J., Horner, R. H., Levin, J. R., Odom, S. L., Rindskopf, D. M., \& Shadish, W. R. (2010). Single-case designs technical documentation. What Works Clearing House website Retrieved from http://ies.ed.gov/ncee/wwc/pdf/reference_resources/wwc_scd.pdf.

LeBlanc, L., \& Gillis, J. (2012). Behavioral interventions for children with autism spectrum disorders. [Review]. Pediatric Clinics of North America, 59(1), 147-164.

Logan, L., Hickman, R., Harris, S., \& Heriza, C. (2008). Single-subject research design: recommendations for levels of evidence and quality rating. Developmental Medicine \& Child Neurology, 50(2), 99-103. 
Lord, C., Wagner, A., Rogers, S., Szatmari, P., Aman, M., Charman, T., . . Yoder, P. (2005). Challenges in Evaluating Psychosocial Interventions for Autistic Spectrum Disorders. Journal of Autism and developmental disorders, 35(6), 695-708.

Lovell, B., Moss, M., \& Wetherell, M. (2012). The psychosocial, endocrine and immune consequences of caring for a child with autism or ADHD. Psychoneuroendocrinology, 37, 534-542. doi: 10.1016/j.psyneuen.2011.08.003

Matson, J. L. (2007). Determining treatment outcome in early intervention programs for autism spectrum disorders: a critical analysis of measurement issues in learning based interventions. Research in Developmental Disabilities, 28(2), 207-218.

Matson, J. L., \& Kozlowski, A. M. (2011). The increasing prevalence of autism spectrum disorders. Research in Autism Spectrum Disorders, 5, 418-425. doi: 10.1016/j.rasd.2010.06.004

Matson, J. L., Turygin, N. C., Beighley, J., \& Matson, M. L. (2012). Status of single-case research designs for evidence-based practice. Research in Autism Spectrum Disorders, 6(2), 931-938.

Mesibov, G. B., \& Shea, V. (2011). Evidence-based practices and autism. [Review]. Autism, 15(1), 114-133.

National Autism Centre. (2009). National Standards Report, The National Standards Projectaddressing the need for evidence based practice guidelines for autism spectrum disorders. Randolph: National Autism Centre.

Odom, S., Brown, W., Frey, T., Karasu, N., Smith-Canter, I., \& Strain, P. (2003). Evidence Based Practice For Young Children with Autism; Contributions of Single Subject Design Research. Focus on Autism \& Other Developmental Disabilities, 18(3), 166-175. 
Odom, S., Hume, K., Boyd, B., \& Stabel, A. (2012). Moving Beyond the Intensive Behavior Treatment Versus Eclectic Dichotomy: Evidence-Based and Individualized Programs for Learners With ASD. Behavior Modification, 36(3), 270-297.

Ottenbacher, K., J. (1986). Evaluating Clinical Change; Strategies for Occupational and Physical Therapists. Baltimore: Williams \& Wilkins.

Parker, R., Vannest, K., \& Davis, J. (2011). Effect size in single-case research: A review of nine nonoverlap techniques. Behaviour Modification, 35(4), 303-322. doi: $10.1177 / 0145445511399147$

Perdices, M., \& Tate, R. (2009). Single-subject designs as a tool for evidence-based clinical practice: Are they unrecognised and undervalued? Neuropsychological Rehabilitation, 19(6), 904-927. doi: 10.1080/09602010903040691

Prior, M., Roberts, J. M. A., Rodger, S., Williams, K., \& Sutherland, R. (2011). A review of the research to identify the most effective models of practice in early intervention of children with autism spectrum disorders. Australian Government Retrieved from http://www.fahcsia.gov.au/sites/default/files/documents/09_2012/review_of the research _report_2011_0.pdf.

Roberts, J. M. A., \& Prior, M. (2006). A review of the research to identify the most effective models of practice in early intervention of children with autism spectrum disorders. (Publications Number:P3-1200). Australian Government Retrieved from http://www.afsaconnect.org.au/uploads/2010/10/autism-review-prior-roberts-2007.pdf.

Smith, T., Scahill, L., Dawson, G., Guthrie, D., Lord, C., Odom, S., . . Wagner, A. (2007). Designing Research Studies on Psychosocial Interventions in Autism. Journal of Autism and Developmental Disorders, 37, 354-366. doi: 10.1007/s10803-006-0173-7 
Stahmer, A. (2007). The Basic Structure of Community Early Intervention Programs for Children with Autism: Provider Descriptions. Journal of Autism and Developmental Disorders, 37, 1344-1354.

Stahmer, A., Schreibman, L., \& Cunningham, a. (2011). Toward a technology of treatment individualization for young children with autism spectrum disorders. Brain Research, 1380, 229-339. doi: 10.1016/brainres.2010.09.043

Strain, P., Schwartz, I., \& Barton, E. (2011). Providing Interventions for Young Children With Autism Spectrum Disorders: What We Still Need to Accomplish. Journal of Early Intervention, 33(4), 321-332. doi: 10.1177/1053815111429970

Tate, R., Mcdonald, S., Perdices, M., Togher, L., Schultz, R., \& Savage, S. (2008). Rating the methodological quality of single-subject designs and n-of-1 trials: Introducing the SingleCase Experimental Design (SCED) Scale. Neuropsychological Rehabilitation, 18(4), 385-401. doi: 10.1080/09602010802009201

Torrey, A. R. (2012). Treatment fidelity instrument to measure a brief opportunistic intervention for prenatal substance use. J Obstet Gynecol Neonatal Nurs, 41(6), 809-820. doi: 10.1111/j.1552-6909.2012.01413.x

Wewers, M. E., \& Lowe, N. K. (1990). A Critical Review of Visual Analogue Scales in the Measurement of Clinical Phenomena. Research in Nursing and Health, 13(4), 227-236.

Wolery, M. (2011). Intervention Research: The importance of fidelity measurement. Topics in Early Childhood Special Education, 31(3), 155-157.

Wolery, M., Busick, M., Reichow, B., \& Barton, E. (2010). Comparison of overlap methods for quantitatively synthesizing single-subject data. The Journal of Special Education, 44(1), 18-28. doi: 10.1177/0022466908328009 


\begin{tabular}{|c|c|c|c|c|c|c|c|c|c|c|}
\hline $\begin{array}{l}\text { Research } \\
\text { Design } \\
\text { Features } \\
\end{array}$ & RCT's & $\begin{array}{l}\text { Non } \\
\text { Random } \\
\text { group }\end{array}$ & Qualitative & $\begin{array}{l}\text { SCD } \\
\text { (ABA) }\end{array}$ & $\begin{array}{l}\text { SCD } \\
\text { (ABAB) }\end{array}$ & $\begin{array}{l}\text { SCD } \\
\text { (ABAC) }\end{array}$ & $\begin{array}{l}\text { SCD } \\
\text { (ABAC- } \\
\text { A) }\end{array}$ & $\begin{array}{l}\text { SCD } \\
\text { Alternating } \\
\text { Treatment }\end{array}$ & \begin{tabular}{|l|} 
SCD \\
Multiple \\
Baseline \\
\end{tabular} & $\begin{array}{l}\text { Case } \\
\text { study }\end{array}$ \\
\hline $\begin{array}{l}\text { Experimental } \\
\text { design }\end{array}$ & (ن) & $(\ddot{)}$ & - & - & $(\ddot{)}$ & (:) & $(\dot{\theta}$ & $(\dot{\theta}$ & $(\dot{\theta}$ & - \\
\hline $\begin{array}{l}\text { No control } \\
\text { group }\end{array}$ & - & - & 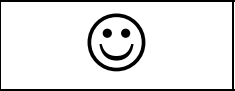 & $(\dot{\theta}$ & (:) & (:) & (:) & (:) & (:) & $(\dot{\theta}$ \\
\hline $\begin{array}{l}\text { Real World } \\
\text { Practice }\end{array}$ & - & - & (:) &  & (:) & (:) & (ن) & (:) & (:) & $(\dot{\theta}$ \\
\hline Low cost & - & - & (ن) & (ن) & (ن) & (ن) & $(\dot{\theta}$ & (ن) & (ن) & (ن) \\
\hline $\begin{array}{l}\text { Small } \\
\text { numbers }\end{array}$ & - & - & (ن) & (ن) & (ن) & (ن) & $(\dot{\theta}$ & (ن) & (ن) & (ن) \\
\hline $\begin{array}{l}\text { Individualising } \\
\text { intervention }\end{array}$ & - & - & (:) & (ن) & (:) & (:) & (:) & (:) & (:) & (ن) \\
\hline $\begin{array}{l}\text { Report } \\
\text { individual } \\
\text { response }\end{array}$ & - & - & (ن) & (ن) & (ن) & (ن) & (:) & (ن) & (ن) & (ن) \\
\hline $\begin{array}{l}\text { Repeated } \\
\text { measurement }\end{array}$ & - & - & - & (ن) & $(\dot{)}$ & (:) & $(\dot{)}$ & (:) & (ن) & - \\
\hline $\begin{array}{l}\text { Does not rely } \\
\text { on withdrawal } \\
\text { of intervention }\end{array}$ & (ن) & (ن) & $\bigodot$ & - & - & (ن) & (ن) & - & (ن) & (ن) \\
\hline $\begin{array}{l}\text { Manages } \\
\text { placebo effect }\end{array}$ & (ن) & (:) & 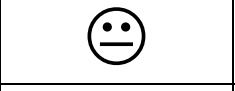 & - & - & $(:)$ & (:) & (:) & - & - \\
\hline $\begin{array}{l}\text { Measures } \\
\text { maintenance }\end{array}$ & $(\dot{)}$ & $(;)$ & 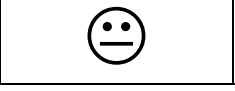 & - & - & - & (:) & $(;)$ & - & - \\
\hline
\end{tabular}

Table 1. Comparison of Research Methods for important features of intervention research in ASD

NOTE: $\odot-$ Yes $\odot-$ Maybe -No 


\section{Reducing Negative Behaviours in Daily Routines for}

\section{Young Children with ASD -Single Case Design Study}

Target Group: 3-5 year olds

Independently confirmed diagnosis of Autistic Disorder and global

developmental delay

Intervention: Management of sensory problems \& Being Responsive Program Target behaviour identified by the family

4 weekly sessions of each intervention

Parent mediated

Family centred

Context: Home based

Community service

Measurement: Parents' perception of the level of the child's behaviour.

Modified visual analogue scale (VAS)

VAS on electronic platform, ( Experience Sampling Program (ESP ${ }^{\mathrm{TM}}$ )

Target behaviour described on VAS

One parent completed the VAS ratings daily

Developmental Behaviour Checklist (DBC) at baseline and follow up

Research Design: ABAC-A/ ACAB-A design

Random allocation to order of intervention

Parents have similar expectations of both interventions

Probe phase 6 months after completion of intervention

6 participants

Fidelity: Audio recordings of all intervention sessions

One session randomly selected from each participant

Review by an independent therapist

Checklist to confirm fidelity

Researcher: Occupational therapist

Provided all intervention sessions

Limited additional funds for equipment \& assessments

Table 2. Contemporary Single Case Design 